\title{
Biology and parasitism rates of Pteromalus nr. myopitae (Hymenoptera: Pteromalidae), a newly discovered parasitoid of olive fruit fly Bactrocera oleae (Diptera: Tephritidae) in coastal California
}

\author{
Therese Kapaun $^{\mathrm{a}, *}$, Hannah Nadel $^{\mathrm{b}}$, David Headrick ${ }^{\mathrm{c}}$, Larisa Vredevoe ${ }^{\mathrm{a}}$ \\ a Biological Sciences Department, California Polytechnic State University, San Luis Obispo, CA 93407, USA \\ ${ }^{\mathrm{b}}$ Department of Entomology, University of California, Riverside, CA 92521, USA \\ ${ }^{\mathrm{c}}$ Horticulture and Crop Sciences Department, California Polytechnic State University, San Luis Obispo, CA 93407, USA
}

\begin{abstract}
A B S T R A C T
An undescribed wasp, Pteromalus nr. myopitae (Hymenoptera: Pteromalidae) opportunistically parasitizes the olive fruit fly Bactrocera oleae (Rossi) (Diptera: Tephritidae), an introduced pest of olives in California. The native or typical host of $P$. nr. myopitae is unknown. We demonstrate that $P$. nr. myopitae is a solitary, ectoparasitic, idiobiont parasitoid of the third instar host inside fruit, and pupation occurs in the host tunnel. Reproduction of $P$. nr. myopitae on B. oleae in olives in the laboratory and in field cages generally failed. Host-feeding was not observed, and adults fed honey and water lived longer than those provided with water alone. Parasitism in non-commercial olives in the moderate coastal climate of San Luis Obispo occurred primarily from August to October, and was absent from a nearby location with more extreme climate and a low population of B. oleae. Greater parasitoid numbers were associated with greater host densities, and proportion of hosts parasitized was generally higher at lower host densities during 2 years of the study. The geographic range of the parasitoid extends along the coast from San Francisco Bay to Ensenada, Baja California, Mexico, and also inland in the Sacramento Valley, with one record in the San Joaquin Valley. The potential of the parasitoid as a biological control agent of $B$. oleae is probably low, however, the extent of its interference with other parasitoids being considered for release in California is unknown and warrants further study.
\end{abstract}

\section{Introduction}

The olive fruit fly, Bactrocera oleae (Rossi) (Diptera: Tephritidae), is an important introduced monophagous pest of olive (Olea europaea L.) that invaded California around 1998, and spread rapidly throughout the state and northern Mexico (Rice et al., 2003). Native to Africa, Asia, and the Mediterranean, this fruit-damaging tephritid is the first in the subfamily Dacinae to establish in California. High densities of $B$. oleae occur along the climatically moderate coastal region, while lower densities occur inland (Rice et al., 2003). Until B. oleae's arrival, the California commercial olive industry mainly battled serious secondary pests such as olive scale, Parlatoria oleae (Colvee), and black scale, Saisettia oleae (Olivier), but these have been successfully controlled mainly through biological and cultural methods (Daane et al., 2005). Establishment of $B$. oleae requires mitigation because of a zero-tolerance policy for infested table fruit by processors (Vossen et al., 2005), and potential for reduced oil quality and quantity.

Olive production for canning and oil is concentrated in the San Joaquin and Sacramento Valleys in the interior of California (Barrio and Carman, 2005), while about $10 \%$ is produced on the coast. The olive is also a popular ornamental tree in urban and rural areas of California. Flowering and fruit set occur from mid to late spring, with harvest occurring in late summer and fall. Fruit become susceptible to B. oleae infestation about 2 months after bloom. The fly lays single eggs directly under the skin of the fruit, and larvae tunnel in the pulp until the mature third instar pupates in the tunnel or exits the fruit to pupate in soil. Before pupating, the third instar tunnels to the fruit surface and scrapes away pulp below the skin, leaving a transparent "window" through which it will exit as a larva or adult. The exit hole permits entry of spoilage organisms that can destroy fruit quality (Vossen et al., 2005).

An apparent lack of effective resident natural enemies spurred the formation of a new classical biological control program against this exotic pest (Hoelmer et al., 2004). Exploration yielded at least five braconid parasitoids from the African continent and associated islands in the Atlantic and Indian Oceans, and another, Psyttalia ponerophaga (Silvestri) from Pakistan (Hoelmer et al., 2004). Most were already known from previous surveys for $B$. oleae parasitoids 
carried out by Silvestri (1914) and Neuenschwander (1982). All are koinobiont larval-pupal parasitoids, except Bracon celer Szépligeti, which is an idiobiont parasitoid of the third instar (Neuenschwander, 1982; Sime et al., 2006). Permits have been issued for release of Psyttalia lounsburyi (Silvestri) and Psyttalia concolor (Szépligeti) after non-target impact assessments were conducted in quarantine at the University of California, Berkeley (Daane et al., 2008).

During surveys of $B$. oleae populations in California for extant natural enemies, a pteromalid (Hymenoptera: Pteromalidae) parasitoid was commonly reared from $B$. oleae-infested olives along coastal California (Pickett and Rodriguez, 2004). Hannes Baur (Natural History Museum, Bern, Switzerland) examined specimens and concluded that this species is similar or perhaps belongs to Pteromalus myopitae (Graham), which parasitizes Myopites species (Diptera: Tephritidae) infesting Inula (Asteraceae) flower heads in Europe (Jennings, 2005), and recommended that the species be referred to as $P$. nr. myopitae (Graham) until its identity is established. No records exist of $P$. myopitae attacking $B$. oleae in Europe or elsewhere.

Whether $P$. nr. myopitae is indigenous or introduced to California is not known, despite a study conducted specifically to locate its native or alternative adopted host (Kapaun, 2007). However, it appears to be established, and therefore its biology and potential as a biological control agent against $B$. oleae merits study. We report herein the results of a study to describe the life history and seasonality of $P$. nr. myopitae and estimate parasitism rates on $B$. oleae on the central California coast from 2004 to 2006. Additionally, we report on a preliminary survey of the parasitoid's geographic range, and explore climatic and host-mediated constraints on its distribution.

\section{Materials and methods}

\subsection{Study sites, climate, and experimental insects}

Four study sites containing ornamental olive trees naturally infested with $B$. oleae were established to monitor fly and parasitoid dynamics (Table 1). Three of these sites were located in moderate coastal climates within San Luis Obispo (SLO), while the fourth site was established $30 \mathrm{~km}$ to the north in Templeton, which is at a slightly higher elevation, and has a climate more characteristic of the inland Central Valley, where the majority of commercial olives are produced. Sites were chosen where fruit were not harvested by owners, no insecticidal treatments were aimed at $B$. oleae, and where olive trees were not in close proximity to other types of fruit trees to reduce the chance of incidental drift from pesticide sprays. Within each site, a cluster of 2-6 mature landscape trees of a single varietal with heavy fruit set and easy access were chosen for monitoring. The SLO sites were surrounded by numerous other landscape olive trees, but the Templeton trees were isolated. The trees did not fit descriptions of commercial cultivars planted in California. Mature fruit measured in Oct. reached a max. of (length $\times$ width) $1.8 \times 1.4 \mathrm{~cm}$ in Monterey Street, $1.9 \times 1.6 \mathrm{~cm}$ in Laurel Lane, and $1.6 \times 1.0 \mathrm{~cm}$ in Grand Avenue.
Daily max. and min. air temperatures for SLO were accessed from the California Irrigation Management Information System (CIMIS) for Nov. 2003 to Nov. 2006. Because CIMIS does not operate a climate station in Templeton, records for this site were accessed from a CIMIS station $8 \mathrm{~km}$ south in Atascadero. Spring (Feb. 1 to May 31) and summer (Jun. 1 to Sept. 30) data were statistically analyzed. Mean max. and min. temperatures at the two stations were compared by paired $t$-tests, while a comparison of 2004-2006 was done by ANOVA followed by Tukey's HSD to compare means. Temperature data were analyzed with JMP 8.0 (SAS, 2008).

During 2004-2006, adult B. oleae and parasitoids were reared from mass collections of approximately 200-300 infested olives from an ornamental tree of an unknown cultivar at the Laurel Lane study site. Experimental parasitoid populations were replenished from fruit that were collected every $2-3$ wk throughout the summer and fall, as our attempts to establish a colony of the parasitoids failed. Fruit were held in $4 \mathrm{~L}$ nylon mesh bags (Trimaco, Durham, NC) under laboratory conditions at California Polytechnic State University, SLO (CPSU) $\left(18-26^{\circ} \mathrm{C}, 25-55 \% \mathrm{RH}\right.$, and a combination of natural and fluorescent lighting under approximately 11:13 L:D). Emerged adult wasps and flies were extracted daily from the bags and isolated in $30 \times 30 \times 30 \mathrm{~cm}$ BugDorm- $1^{\infty}$ rearing cages (BioQuip Products, Inc., Rancho Dominguez, CA) with mesh and translucent polypropylene-sheet walls. Food for flies and parasitoids was supplied as equal volumes of honey, yeast extract (Fisher Biotech, Fairlawn, NJ), and water, streaked onto the walls of the cage, and replaced every few days as needed. Water was provided ad libitum in a glass vial with a cotton plug.

\subsection{Parasitoid taxonomy}

The pteromalid wasps that emerged from olives were compared to the extensive University of California, Riverside (UCR) tephritid parasitoid collection to determine if they had been previously found in California and if they could be associated with other host species. Additionally, pinned specimens (20 female and 2 male) were sent to H. Baur to confirm that they belong to the same species previously reared from California olives by Pickett and Rodriguez (2004).

\subsection{Parasitoid biology}

\subsubsection{Host-stage preference and oviposition behavior}

Fruit containing eggs or first through third instars of $B$. oleae were produced by controlled infestation. Uninfested Manzanillo olives were shipped overnight from the University of California Kearney Agricultural Center in Parlier, CA, (KAC) and refrigerated until use. Infested olives were produced by exposing 100 uninfested olives to 20 mated female $B$. oleae in a cage for approximately $48 \mathrm{~h}$. Olives with 2-3 oviposition marks were selected for parasitoid oviposition studies. Host stages present in fruit were determined by random dissections of at least five infested olives per batch of 100 .

Table 1

Location and description of study sites for weekly olive sampling. All study sites are in San Luis Obispo County, California.

\begin{tabular}{|c|c|c|c|c|}
\hline Study Site & City & Coordinates & Elevation $(\mathrm{m})$ & Description \\
\hline Grand Avenue & $\begin{array}{l}\text { San Luis } \\
\text { Obispo }\end{array}$ & $\begin{array}{l}\text { N } 35^{\circ} 17^{\prime} 49.57^{\prime \prime} \\
\text { W } 120^{\circ} 39^{\prime} 12.09^{\prime \prime}\end{array}$ & 123 & Dry residential landscape; six mature olive trees within $50 \mathrm{~m}$ \\
\hline Monterey Street & $\begin{array}{l}\text { San Luis } \\
\text { Obispo }\end{array}$ & $\begin{array}{l}\text { N } 35^{\circ} 17^{\prime} 19.89^{\prime \prime} \\
\text { W } 120^{\circ} 39^{\prime} 06.49^{\prime \prime}\end{array}$ & 90 & Irrigated commercial landscape; two mature olive trees within $100 \mathrm{~m}$ \\
\hline Laurel Lane & $\begin{array}{l}\text { San Luis } \\
\text { Obispo }\end{array}$ & $\begin{array}{l}\text { N } 35^{\circ} 16^{\prime} 01.13^{\prime \prime} \\
\text { W } 120^{\circ} 38^{\prime} 22.86^{\prime \prime}\end{array}$ & 104 & Dry residential landscape; four mature olive trees within $50 \mathrm{~m}$ \\
\hline Duncan Road & Templeton & $\begin{array}{l}\text { N } 35^{\circ} 33^{\prime} 21.88^{\prime \prime} \\
\text { W } 120^{\circ} 42^{\prime} 43.02^{\prime \prime}\end{array}$ & 256 & Dry commercial landscape; four mature olive trees within $50 \mathrm{~m}$ \\
\hline
\end{tabular}


To determine the host stage preferred for parasitism, experiments were conducted under laboratory conditions $\left(18-26{ }^{\circ} \mathrm{C}\right.$, $25-55 \% \mathrm{RH}$, and natural and fluorescent lighting of approximately 11:13 L:D) between Oct. and Nov. 2004. Four groups of 10 olives, each containing a different host stage (eggs, first, second, or third instars) were placed on the floor of a single BugDorm $-1^{\mathscr{6}}$ cage provisioned with food and water (described previously), with each olive group separated by approximately $10 \mathrm{~cm}$. Ten mated female parasitoids were released into the cage and host searching and oviposition behaviors were recorded for $15 \mathrm{~min}$ at the start of each hour between 09:00 and 14:00 for two consecutive days. After $48 \mathrm{~h}$ the parasitoids were removed from the cage and the fruit left in place to permit progeny development. This experiment was replicated 12 times.

Progeny production on picked fruit during the host-stage preference study was extremely rare. We therefore dissected field-collected olives with signs of fly infestation under a stereo microscope to record host instar when parasitoid larvae and pupae were present. We also attempted to determine if parasitoid reproduction could be improved by using unpicked fruit in the field. The study was performed on a mature tree on the campus of CPSU. Two branches with young olive fruit were isolated inside $4 \mathrm{~m}$ long nylon mesh sleeve cages during Aug. 2006, before B. oleae oviposition activity began. By early Sept. the fruit were mature enough to support fly development, as evidenced by the presence of larvae in olives on exposed adjacent branches. To infest olives, all except 50 fruit were removed from the branch inside a sleeve, and 10 mated female flies were placed into the sleeve to oviposit for $48 \mathrm{~h}$, after which the flies were removed. Larval developmental stage was determined by random fruit dissections every $2-3 \mathrm{~d}$. Because our picked fruit studies had previously revealed that the parasitoid preferentially attacked third instar B. oleae, we placed 10 mated female parasitoids into the sleeve when larvae reached third instar in late Sept. After $3 \mathrm{~d}$ the parasitoids were removed and the sleeve was monitored every 2-3 d for host and parasitoid emergences. All emerged insects were recorded and removed from the sleeve to prevent further oviposition. After $10 \mathrm{wk}$ the fruit were removed from the sleeve and dissected to determine whether unemerged parasitoids were present. A trial using the second sleeve cage was repeated in late Sept., and parasitoids were added approximately 1 month later after third instar hosts were detected. Because no parasitoids emerged from these trials, no analyses were performed on these data.

\subsubsection{Developmental period and adult longevity}

Due to poor progeny production under experimental conditions, emergence of $P$. nr. myopitae from dated field collections of olives (used for production of experimental insects and for study of host and parasitoid dynamics) were used to estimate male and female developmental periods under both laboratory $\left(18-26^{\circ} \mathrm{C}, 25-55 \% \mathrm{RH}\right)$ and shaded outdoor $\left(6.5-33.8^{\circ} \mathrm{C}, 22-\right.$ $96 \% \mathrm{RH}$ ) conditions. Max. emergence intervals for each sex were assumed to approximate the period of development from egg to adult.

Adult longevity was determined in the laboratory with and without honey as food. Newly emerged adult parasitoids were housed individually in the laboratory $\left(18-26{ }^{\circ} \mathrm{C}, 25-55 \% \mathrm{RH}\right.$, and a combination of natural and fluorescent lighting of approximately 11:13 L:D) in clear plastic 50 dram vials with mesh lids. Twelve female and eight male parasitoids were provided a solution of equal volumes of honey and water streaked inside each vial, while nine female and six male parasitoids were not provisioned with honey. All vials were provisioned with water ad libitum as described previously. Parasitoid mortality was recorded daily. Longevity with food and water or only water were analyzed separately for each sex by $t$-test at $\alpha=0.05$ (Minitab, 2008).

\subsubsection{Courtship and mating behavior}

Courtship and mating behaviors were observed and sequences documented as potentially useful traits for future studies on rearing methods and systematics of $P$. nr. myopitae. Five newly emerged $(<1$-d-old) male and 10 newly emerged virgin female wasps were placed together in a BugDorm- $1^{\infty}$ cage provisioned with food and water (described previously). Additional observations were made on five 2- to 5-d-old virgin males and ten 5- to 10 -d-old virgin females. Sequences of courtship and copulatory behaviors were recorded for $15 \mathrm{~min}$ at the start of each hour between 09:00 and 14:00 for two consecutive d. Females that appeared to have mated were retained for use in host-stage preference and oviposition studies.

\subsection{Seasonal host and parasitoid dynamics}

One hundred olives were collected weekly from each of the four SLO County study sites during 2004-2006 to monitor host and parasitoid population fluctuations over time and to calculate parasitism rates. Olives were randomly picked from all aspects (north, south, east, and west) of trees at heights of approximately 1-2 $\mathrm{m}$, placed into $4 \mathrm{~L}$ sealed mesh bags (described previously), and transported in an ice chest to the laboratory. During 2004, the bags were held at CPSU under laboratory conditions (18$26{ }^{\circ} \mathrm{C}, 25-55 \% \mathrm{RH}$, and a combination of natural and fluorescent lighting of approximately 12:12 L:D), whereas in 2005 and 2006, the bags were held in an outdoor shaded area in SLO under natural conditions $\left(6.5-33.8^{\circ} \mathrm{C}, 22-96 \% \mathrm{RH}\right.$, and natural light of approximately 11:13 L:D). Emerged flies and parasitoids were counted and removed daily, and parasitoid sex was documented to calculate sex ratio. After $60 \mathrm{~d}$ the samples were discarded, as it was presumed that emergence was complete by that time. The number of consecutive weeks per year during which olive samples were taken varied due to environmental conditions that affected olive phenology. Olive collection began when fruit matured sufficiently to support larval fly development and halted when rapid fruit drop occurred at the end of the growing season. Dropped fruit were not sampled during this study due to potential effects by fungi and predatory insects on host and parasitoid development.

Host number per sample was estimated as the sum of the number of adult flies and parasitoids emerged in the sample (including 22 individuals of other chalcidoid wasps). Proportion parasitism by $P$. nr. myopitae was calculated from emerged insects as the number of $P$. nr. myopitae divided by the sum of $B$. oleae and $P$. nr. myopitae. Proportion parasitism data were arcsin square-root transformed, and numbers of flies and parasitoids were transformed by square-root $(x+0.5)$ to normalize residuals and stabilize variances before statistical analysis. Effects of site and year on abundance of $B$. oleae and P. nr. myopitae, and on proportion of hosts parasitized, were analyzed by repeated-measures ANOVA. Interactions and week-of-year effects were not analyzed due to insufficient degrees of freedom for these tests. Because sampling began late (wk 37) in 2004 after host populations were at or near their seasonal peak, and olives dropped completely at different times each year, only data from wk 37 to 44 (mid-Sept. to late Oct., 2004-2006) were subjected to repeated-measures analysis. Significant effects were subjected to a posteriori linear contrasts to separate mean differences. Influence of host numbers and sites on parasitoid number and proportion parasitism within each year was further explored with analysis of covariance, using host numbers as the covariate. Mean site effects were compared by Tukey's HSD when significant. Because few parasitoids emerged in SLO in 2006 and none emerged from Templeton in any year, 2006 and Templeton data were excluded from parasitoid analyses. Analyses were made with JMP 8.0 (SAS, 2008). 


\subsection{Parasitoid geographic range}

Because sampling in 2003 and 2004 revealed that the parasitoid appeared to be common in coastal regions of SLO and Santa Barbara Counties, but absent from the San Joaquin Valley (Nadel, personal observation), a preliminary survey was made to explore the coastal geographic range of the parasitoid. Additional information became available from ongoing $B$. oleae research in inland California to broadly define the wasp's inland range. Our survey consisted of single samples of 100-200 olives from ornamental trees (unknown varietals) taken from 31 sites in 22 cities between Aug. and Nov. 2006. The collection period was chosen to coincide with our collection records from SLO County. All sites were within $40 \mathrm{~km}$ of the Pacific Ocean shoreline; most with temperate Mediterranean climates. Since coastal olive trees are relatively scarce north of San Francisco Bay, our northernmost survey point was Monterey, CA. Our southernmost point was Ensenada, Baja California, Mexico. Picked fruit were placed into sealed mesh bags (described previously) and transported in an ice chest to a shaded area in SLO under outdoor conditions $\left(5.7-33.1^{\circ} \mathrm{C}, 10-96 \% \mathrm{RH}\right.$, and natural light), where they were held for $60 \mathrm{~d}$ and monitored daily for fly and parasitoid emergence. Presence or absence of $B$. oleae and numbers of emerged $P$. nr. myopitae were recorded in each sample.

\section{Results}

\subsection{Climate}

A comparison between the two study cities showed that Templeton experienced greater temperature extremes than SLO. Max. spring temperatures averaged significantly higher in Templeton $\left(20.4{ }^{\circ} \mathrm{C} \pm 0.3\right)$ than in SLO $\left(19.5^{\circ} \mathrm{C} \pm 0.2\right)$ (paired $t$-test, $d f=340$, $t=5.87, P<0.001)$, and min. temperatures in Templeton $\left(4.5^{\circ} \mathrm{C} \pm\right.$ 0.2 ) were significantly lower than in $\operatorname{SLO}\left(7.9{ }^{\circ} \mathrm{C} \pm 0.2\right)$ (paired $t$-test, $d f=330, t=26.65, P<0.001)$. Similarly, during summer, max. average temperatures in Templeton $\left(29.9{ }^{\circ} \mathrm{C} \pm 0.3\right)$ averaged significantly higher than in SLO $\left(24.3^{\circ} \mathrm{C} \pm 0.2\right)$ (paired $t$-test, $d f=351$, $t=30.40, P<0.001$ ), while min. average temperatures in Templeton $\left(9.5^{\circ} \mathrm{C} \pm 0.2\right)$ were significantly lower than in SLO $\left(11.8^{\circ} \mathrm{C} \pm 0.1\right)$ (paired $t$-test, $d f=351, t=16.54, P<0.001$ ). A comparison across study years showed that spring temperatures generally declined between 2004 and 2006, with max. and min. temperatures at their lowest levels during 2006 in both sites (Table 2). Summer temperatures did not change consistently in both sites with year.

\subsection{Parasitoid taxonomy}

Baur (personal communication) confirmed that the specimens we sent were conspecific with those sent previously by other researchers in California, and concluded that the parasitoid is an undescribed species with no host records. He determined that the specimens are very similar to the European P. myopitae, whose locality records show a range limited to England, France, Spain, Sweden, and Italy (Universal Chalcidoidea Database, 2007). Parasitoid specimens associated with California Tephritidae from the UCR collection included no specimens of $P$. nr. myopitae. Two notable morphological characteristics of this species that may assist in future taxonomic identification include the dark metallic blue color of both sexes, and the exceptionally long, tapering abdomen of the female (Fig. 1). A species description is in preparation (Heydon, personal communication). Voucher specimens of $P$. nr. myopitae are deposited in the entomological biological control collection at the Horticulture and Crop Science Department, CPSU.

\subsection{Parasitoid biology}

\subsubsection{Host-stage preference and oviposition behavior}

The laboratory host-stage preference study yielded only one parasitoid offspring, from a third instar host that developed from an egg laid 12-14 d earlier. Data from field-collected fruit were therefore used to determine host-stage preference. Dissections of 300 randomly picked infested olives from Laurel Lane between Jul. and Dec. 2004-2006 revealed 38 solitary parasitoid larvae and pupae, all on or near the immobilized or dead third instar host. Attempts were made to rear some of these larvae and pupae by enclosing them with the host inside the fruit in which they were found, and placing the fruit in covered plastic dishes. Four parasitoid larvae and two pupae were successfully reared to adulthood in this manner and confirmed to be $P$. nr. myopitae. Based upon these

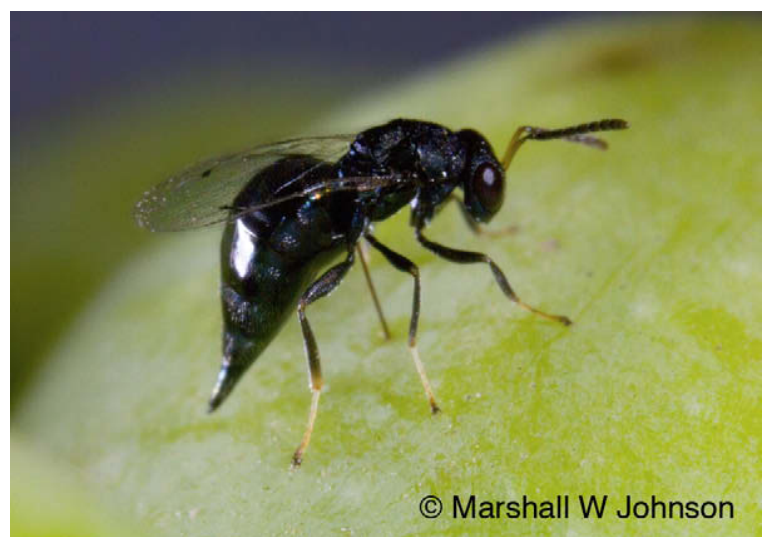

Fig. 1. Female Pteromalus nr. myopitae ovipositing through the surface of an olive fruit. Photo by Marshall W. Johnson.

Table 2

Comparison of mean $\left( \pm\right.$ SEM) high and low temperatures $\left({ }^{\circ} \mathrm{C}\right)$ recorded in spring and summer 2004-2006 in San Luis Obispo and Templeton ${ }^{\mathrm{a}}$, California $($ ANOVA).

\begin{tabular}{|c|c|c|c|c|c|c|c|c|}
\hline \multirow[t]{3}{*}{ Year } & \multicolumn{4}{|l|}{ Spring $^{\mathrm{b}}$} & \multicolumn{4}{|l|}{ Summer $^{\mathrm{c}}$} \\
\hline & \multicolumn{2}{|l|}{ SLO } & \multicolumn{2}{|l|}{ Templeton } & \multicolumn{2}{|l|}{ SLO } & \multicolumn{2}{|l|}{ Templeton } \\
\hline & High & Low & High & Low & High & Low & High & Low \\
\hline 2004 & $20.5 \pm 0.4 a$ & $8.3 \pm 0.2 a$ & $23.2 \pm 0.6 a$ & $4.4 \pm 0.2 \mathrm{ab}$ & $24.9 \pm 0.3 a$ & $12.0 \pm 0.2 \mathrm{a}$ & $29.9 \pm 0.4 a$ & $9.5 \pm 0.3 a$ \\
\hline 2005 & $19.4 \pm 0.3 \mathrm{ab}$ & $7.8 \pm 0.2 \mathrm{ab}$ & $19.9 \pm 0.4 b$ & $5.3 \pm 0.3 a$ & $23.7 \pm 0.3 b$ & $11.0 \pm 0.2 b$ & $29.8 \pm 0.5 a$ & $9.4 \pm 0.3 a$ \\
\hline 2006 & $18.3 \pm 0.4 b$ & $7.2 \pm 0.3 b$ & $19.1 \pm 0.6 b$ & $3.8 \pm 0.4 b$ & $24.4 \pm 0.3 \mathrm{ab}$ & $12.1 \pm 0.2 \mathrm{a}$ & $30.0 \pm 0.4 a$ & $9.7 \pm 0.3 a$ \\
\hline$F$ & 7.41 & 4.36 & 16.0 & 6.56 & 3.53 & 14.43 & 0.02 & 0.20 \\
\hline$d f$ & 2 & 2 & 2 & 2 & 2 & 2 & 2 & 2 \\
\hline$P$ & $<0.001$ & 0.014 & $<0.001$ & 0.002 & 0.030 & $<0.001$ & 0.976 & 0.816 \\
\hline
\end{tabular}

Means within a column followed by different letters are significantly different (Tukey's HSD test).

a Templeton data are represented by the nearest climate station at Atascadero.

b Feb. 1 to May 31.

c Jun. 1 to Sept. 30. 
observations we determined that $P$. nr. myopitae is a solitary, idiobiont, ectoparasitoid of third instar B. oleae.

Efforts to establish a laboratory colony failed, possibly due to the unsuitability of picked fruit. Attempts to rear $P$. $n$ r. myopitae on unpicked fruit in field cages were also unsuccessful. Adult $B$. oleae were reared from unpicked fruit, but no parasitoid offspring emerged. None of the $P$. nr. myopitae placed in field cages were observed to investigate or oviposit in fruit. The proportion of fruit infested by B. oleae was 0.72 for the cage infested in Aug., and 0.74 for the cage infested in Sept.

Fruit condition appeared to influence parasitoid oviposition choice. Unripe green olives desiccated quickly after picking, while ripe olives tended to become oily and moldy. Dry olives were typically ignored by the parasitoid, perhaps because the host larvae were dead, and parasitoids walking across oily olives were often observed to spend extensive time grooming themselves, either on or off the fruit. In general, picked fruit were rejected by parasitoids, which sometimes spent up to $2 \mathrm{~h}$ moving over the olive surface without probing and subsequently moved onto other fruits.

Female parasitoids were observed $(n=18)$ to probe from the exterior of the fruit (Fig. 1), and were never observed to probe or oviposit through "windows", nor enter larval tunnels in search of hosts. Before probing, females simultaneously walked and antennated the fruit surface, eventually standing motionless while appearing to antennate the fruit for up to 20 min until the ovipositor was inserted. The abdomen was raised and the tip of the ovipositor exerted slightly before insertion into the fruit. An individual often probed briefly in several sites in close proximity $(<3 \mathrm{~mm})$, repeating this probing behavior up to five times within $5 \mathrm{~min}$. Host-feeding was not observed. Although the number of observed probes was small, only one probe was observed in an olive with a first instar, while nine and eight probes were made into olives with second and third instars, respectively, suggesting that older instars are more easily detected or preferred.

Morphology of parasitoid larvae encountered in dissected fruit revealed that there is an early planidial instar that is white, setose, and tapered at the caudal end. Later instars are grayish-brown and bare. Parasitized host cadavers turned dark brown and later became shriveled and black as parasitoid feeding continued. Parasitoid larvae never completely consumed the host, and pupated inside the fruit next to the shriveled host remains. Upon emergence, adult wasps exited the fruit by chewing a small $(<1 \mathrm{~mm}$ diam), round, exit tunnel to the surface. Pupal exuviae remaining near host cadavers were transparent, yellowish, and shiny, and, when shed by a female, clearly exhibited the shape of the elongated, tapering abdomen.

Adult sex ratio, expressed as a percentage of female $P$. nr. myopitae reared from field material was $83.3 \%(n=72)$ in $2004,70.5 \%$ $(n=146)$ in $2005,100 \%(n=2)$ in 2006 , and was highly femalebiased (75.0\%) overall.

\subsubsection{Developmental period and adult longevity}

In 2004, when weekly fruit samples were kept indoors, emergence time span for females $(n=60)$ was max. $20 \mathrm{~d}$, min. $1 \mathrm{~d}$, with a mean of $8.6 \pm 0.7 \mathrm{~d}$, and for males $(n=12)$ was max. $24 \mathrm{~d}$, min. 2 $\mathrm{d}$, and mean $10.2 \pm 1.9 \mathrm{~d}$. However, the single parasitoid offspring that developed in the laboratory from the host-preference study was a female that emerged $28 \mathrm{~d}$ after the host was exposed to a female parasitoid. In 2005, weekly samples were kept outdoors, and females $(n=103)$ emerged at max. $37 \mathrm{~d}$, min. $0 \mathrm{~d}$., and mean $16.2 \pm 0.9 \mathrm{~d}$, while males $(n=43)$ emerged at max. $33 \mathrm{~d}$, min. $0 \mathrm{~d}$, and mean $14.1 \pm 1.3 \mathrm{~d}$. Max. outdoor emergence intervals for each sex may approximate their natural developmental time in the field, i.e. about $5 \mathrm{wk}$ for females and a few days less for males, while development appeared to be more rapid indoors.
Female parasitoids lived an average of $60.0 \pm 6.4 \mathrm{~d}$ (range 11 $89, n=12$ ) under laboratory conditions when provided with honey and water, and males lived an average of $32.9 \pm 1.4 \mathrm{~d}$ (range 6-74, $n=8$ ). Parasitoids provided with only water had significantly shorter life spans; average female longevity was $9.4 \pm 2.9 \mathrm{~d}$ (range $7-12, n=9$ ), and average male longevity was $8.8 \pm 2.0 \mathrm{~d}$ (range 3 $19, n=6$ ). Longevity of each sex was significantly greater with honey as food ( $t$-test; females: $d f=11, P<0.001$; males: $d f=7$, $P=0.034)$.

\subsubsection{Courtship and mating behavior}

Caged males and females were observed courting and mating ( $n=17$ pairs). Males approached females and usually the pair stopped walking at about $1 \mathrm{~cm}$ apart, faced each other, and then antennated with the tips of their antennae while standing motionless. In some cases, males were rejected at this point and moved away, while in others, the male climbed onto the female's dorsum, where he stood on or just behind her head and the pair antennated for up to $30 \mathrm{~s}$. Frequently, males were rejected by the female after initiating this antennation phase on the female's dorsum. If courtship continued, the male turned $180^{\circ}$ on the female's dorsum and moved toward the female's posterior end until his face was above her abdomen, and then turned again and moved toward his original position above the female's head. This was repeated up to four times. If the female was receptive, the male then moved backward and keeping his long body axis parallel to the female's, rotated about $90^{\circ}$ to stand on the side of the female's abdomen and reached the tip of his abdomen to her gonopore to initiate copulation (Fig. 2). The courtship and copulatory behaviors of $P$. nr. myopitae are very similar to those described for Pteromalus coloradensis (Ashmead) by Headrick and Goeden (1989), who noted that the peculiar side-mounting of the female by the male had been not been previously recorded in the genus and may be useful for taxonomic studies.

\subsection{Seasonal host and parasitoid dynamics}

During the course of the study, 7506 adult B. oleae and 224 adult $P$. nr. myopitae were reared from weekly samples of field-collected olives. Host numbers peaked at different weeks in each site and generally were declining by weeks $41-44$ (Oct.) in SLO (Fig. 3 ) before olives dropped from the trees and sampling ended. In Templeton the host season began and declined later than in SLO. No P. nr. myopitae emerged from Templeton samples, and the parasitoid is therefore assumed to be absent from that site. Host numbers were significantly higher in Laurel Lane and Monterey Street compared with Grand Avenue and Templeton (Table 3). Pteromalus nr. myopitae numbers were not significantly different among SLO sites but proportion parasitism was significantly higher in Grand Avenue (Table 3). Fly abundance declined during the study years and was

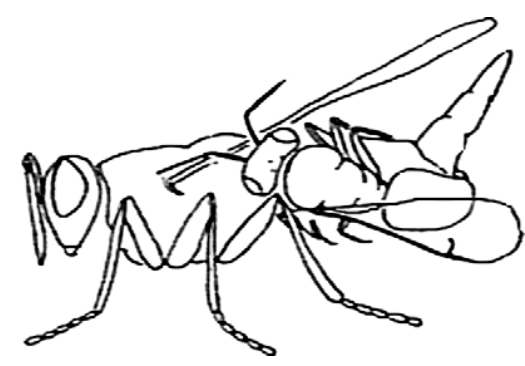

Fig. 2. Diagrammatic representation of male and female Pteromalus coloradensis (Ashmead) position during copulation, which resembles the copulatory position of Pteromalus nr. myopitae. Male drawn with right pair of wings removed. Reproduced from Headrick and Goeden (1989). 


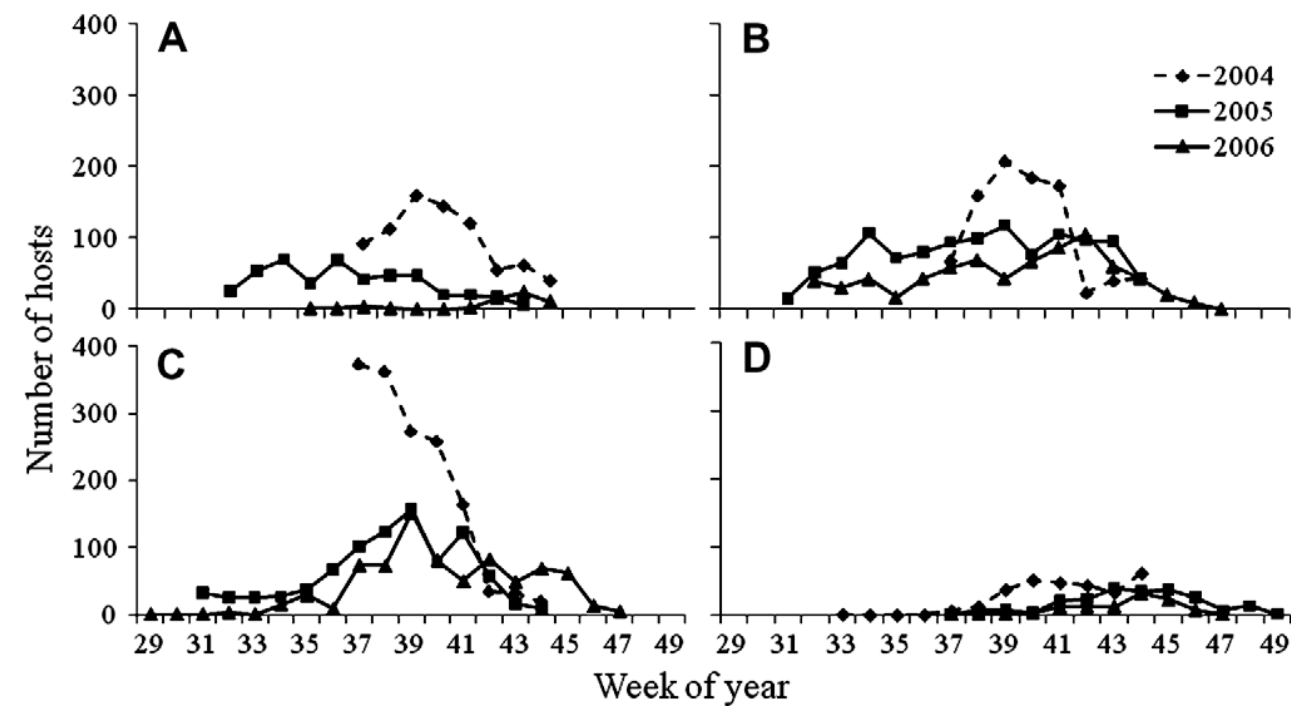

Fig. 3. Number of hosts (estimated as the sum of Bactrocera oleae and parasitoids) emerged from weekly samples of 100 olives in 2004-2006 at sites in San Luis Obispo (A-C) and Templeton (D). (A) Grand Avenue; (B) Monterey Street; (C) Laurel Lane; (D) Duncan Road.

Table 3

Repeated-measures ANOVA on numbers of Bactrocera oleae hosts and Pteromalus nr. myopitae and proportion of hosts parasitized among sites and years. Data analyzed were from weeks 37 to 44 (mid-Sept. to late Oct.), when samples were taken from all years. Before analysis, host and parasitoid numbers were square-root-transformed and proportional parasitism data were arcsin-square-root transformed. Templeton data were excluded from analyses on parasitoids. Means were separated by $a$ posteriori linear contrasts.

\begin{tabular}{|c|c|c|c|c|c|c|}
\hline \multirow[b]{2}{*}{ Site } & \multicolumn{2}{|l|}{ Hosts } & \multicolumn{2}{|l|}{ Parasitoids } & \multicolumn{2}{|c|}{ Proportion parasitized } \\
\hline & $d f$ & $F$ & $d f$ & $F$ & $d f$ & $F$ \\
\hline & 3,6 & $14.68^{* *}$ & 2,4 & 1.39 & 2,4 & 3.07 \\
\hline & Mean \pm SEM & Mean \pm SEM & Mean \pm SEM & & & \\
\hline$L^{\mathrm{a}}$ & $118.6 \pm 20.94 a$ & $2.1 \pm 0.51 \mathrm{a}$ & $0.03 \pm 0.01 b$ & & & \\
\hline MS & $90.5 \pm 9.93 a$ & $2.3 \pm 0.49 a$ & $0.02 \pm 0.00 \mathrm{~b}$ & & & \\
\hline GA & $45.6 \pm 9.74 b$ & $3.6 \pm 0.78 a$ & $0.11 \pm 0.03 a$ & & & \\
\hline $\mathrm{TE}$ & $20.8 \pm 3.78 b$ & - & - & & & \\
\hline \multirow[t]{3}{*}{ Year } & $d f$ & $F$ & $d f$ & $F$ & $d f$ & $F$ \\
\hline & 2,6 & $10.34^{*}$ & 2,4 & $22.66^{* *}$ & 2,4 & $11.70^{*}$ \\
\hline & Mean \pm SEM & Mean \pm SEM & Mean \pm SEM & & & \\
\hline 2004 & $109.5 \pm 17.50 a$ & $3.6 \pm 0.63 a$ & $0.04 \pm 0.01 \mathrm{ab}$ & & & \\
\hline 2005 & $56.6 \pm 8.00 \mathrm{~b}$ & $4.4 \pm 0.54 a$ & $0.13 \pm 0.03 a$ & & & \\
\hline 2006 & $40.5 \pm 6.78 b$ & $0.00 \mathrm{~b}$ & $0.00 \mathrm{~b}$ & & & \\
\hline
\end{tabular}

Means within a column followed by different letters are significantly different.

${ }^{a}$ LL, Laurel Lane; MS, Monterey Street; GA, Grand Avenue; TE, Templeton.

${ }^{*} P<0.05$.

${ }^{* * *} P<0.01$.

significantly lower in 2005 and 2006 than in 2004. Only two $P$. nr. myopitae emerged from samples in 2006, which was a significant decline from the previous years. Proportion parasitism was highest in 2005 (Fig. 4) but not statistically different from 2004, and it was significantly lower in 2006 compared with 2004 (Table 3). The average parasitism rate by $P$. nr. myopitae from all samples was $3 \%$. The highest individual weekly parasitism rate was 33\% from a sample taken at Grand Avenue on 10/22/05 that produced only four B. oleae and two P. nr. myopitae.

Analyses of covariance indicated that $P$. nr. myopitae numbers were significantly influenced by host numbers in 2004 and 2005 (Table 4). Resulting regressions showed that numbers of parasitoids generally rise with host numbers (Fig. 5). Proportion parasitism was significantly influenced by host abundance in 2005, and regressions showed that parasitism was negatively correlated with increasing host abundance (Fig. 5). Site had a significant influence on both parasitoid number and parasitism level in 2004, with Grand Avenue having a significantly higher influence on numbers of parasitoids and proportion parasitism than other SLO sites ( $\mathrm{Tu}-$ key's HSD, $P<0.05$ ). There were no interaction effects between site and host abundance in the analyses of covariance, and they were therefore not included in the analyses.

Although uncommon, other parasitoids emerged from infested olives, but were generally not identified beyond family level. Eupelmid (Hymenoptera: Eupelmidae) wasps emerged occasionally from field samples that yielded both $B$. oleae and $P$. nr. myopitae. In 2004, 12 eupelmids emerged from SLO collections, and in 2005, 10 eupelmids emerged, but none emerged in 2006. These numbers were included in estimates of host abundance. In all cases, eupelmids emerged from samples containing $P$. nr. myopitae, which suggests that they may be hyperparasitoids of this species. Eupelmids are often reported as facultative hyperparasitoids of chalcidoid wasps (Goulet and Huber, 1993). In 2004, two eulophid (Hymenoptera: Eulophidae) wasps emerged from SLO field material that was not intended for monitoring weekly percent parasitism. Two other wasps emerged in 2005 from Templeton field 


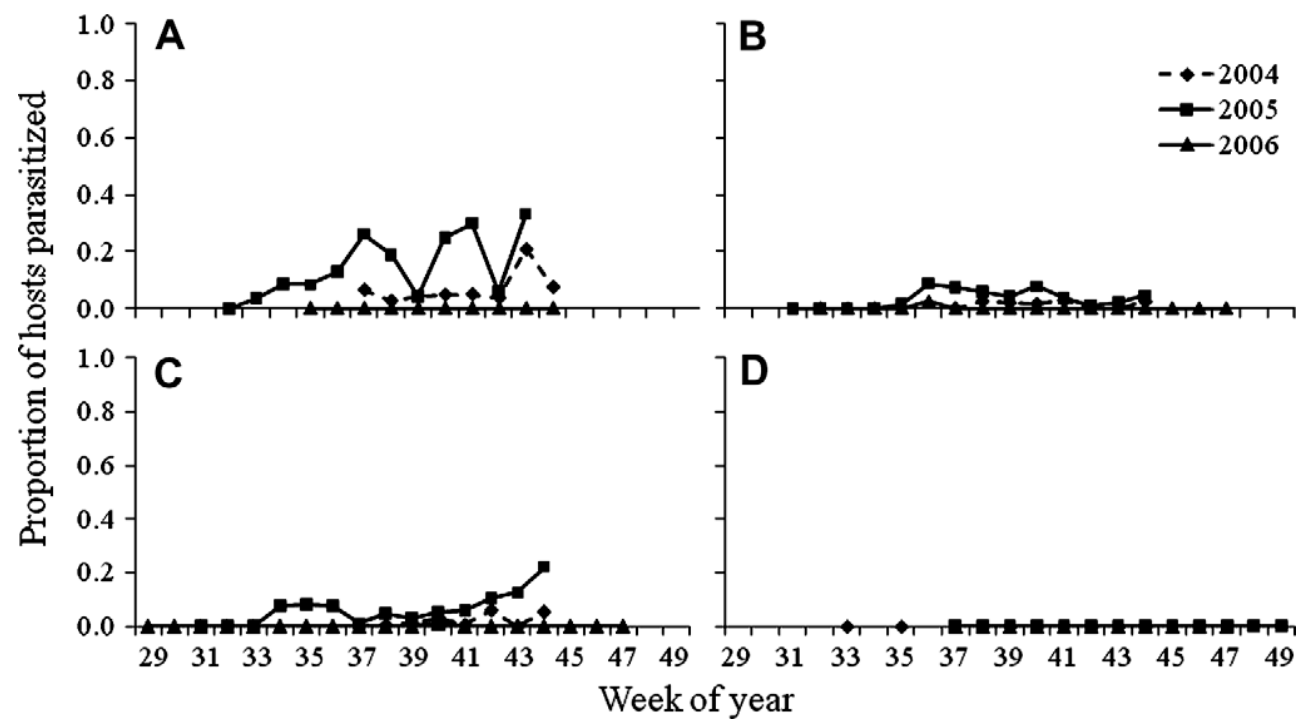

Fig. 4. Proportion of Bactrocera oleae parasitized by Pteromalus nr. myopitae during the olive growing season in San Luis Obispo (A-C) and Templeton (D). (A) Grand Avenue; (B) Monterey Street; (C) Laurel Lane; (D) Duncan Road.

Table 4

Analysis of covariance table of Pteromalus nr. myopitae numbers (square-root transformed) and proportion parasitism (arcsin-square-root transformed) in San Luis Obispo sites during 2004 and 2005. Host numbers (square-root transformed) were used as the covariate. Interactions between site and host numbers were not significant and were excluded from the analyses.

\begin{tabular}{|c|c|c|c|c|c|c|}
\hline & \multicolumn{3}{|c|}{ Parasitoid number } & \multicolumn{3}{|c|}{ Proportion parasitism } \\
\hline & $d f$ & Mean square & $F$ & $d f$ & Mean square & $F$ \\
\hline \multicolumn{7}{|l|}{2004} \\
\hline Site & 2 & 2.5247 & $7.2257^{* *}$ & 2 & 0.0552 & $5.7661^{*}$ \\
\hline Hosts & 1 & 2.2769 & $6.5166^{*}$ & 1 & 0.0031 & 0.324 \\
\hline Error & 20 & & & 20 & & \\
\hline Total & 23 & & & 23 & & \\
\hline \multicolumn{7}{|l|}{2005} \\
\hline Site & 2 & 0.6315 & 1.9221 & 2 & 0.0409 & 2.2296 \\
\hline Hosts & 1 & 1.8348 & $5.5848^{*}$ & 1 & 0.1206 & $6.5789^{*}$ \\
\hline Error & 20 & & & 20 & & \\
\hline Total & 23 & & & 23 & & \\
\hline
\end{tabular}

material, one Mesopelobus sp. (Hymenoptera: Pteromalidae), and one ichneumonid (Hymenoptera: Ichneumonidae). The host species were not identifiable due to the deteriorated state of the fruit.

\subsection{Parasitoid geographic range}

Pteromalus nr. myopitae emerged from about half the samples and was found from SLO southward to Ensenada, Baja California, Mexico (Fig. 6). Adult B. oleae, however, emerged from all samples. Outside SLO County, the largest number (25) of parasitoids emerged from olives sampled in Los Angeles County. No parasitoids emerged from fly-infested olives taken from Monterey and Ventura Counties. Information solicited from several B. oleae researchers who collectively reared olives from throughout California revealed that the parasitoid was regularly found in Alameda County in the San Francisco Bay area (Opp, personal communication), Yolo, Butte, and Solano Counties in the Sacramento Valley (Burrack, personal communication), and Riverside County (Pickett and Rodriguez, 2004) in the southern part of the state. We found the exuviae and meconium of one female next to a third instar $B$. oleae cadaver in Fresno County in the San Joaquin Valley although we dissected thousands of olives from Fresno and Tulare Counties between 2003 and 2005

\section{Discussion}

Pteromalus nr. myopitae is a solitary, idiobiont, ectoparasitoid that oviposits in third instar hosts. The reason for its failure to reproduce in cages under the tested laboratory and field conditions remains unknown, but a common factor under all cage conditions was reluctance by the parasitoid to initiate probing. Several reasons may have contributed to this, including the condition of picked olives, confinement in cages, and poor nutrition. Once picked, mature olives rapidly become oily, infected with fungi and other microflora, and often rot, especially if infested by B. oleae. Less mature fruit may desiccate. Therefore, poor fruit quality may be a reason that female wasps often rejected infested fruit in laboratory cages and failed to probe or oviposit, and in cases where oviposition occurred, olive microflora may have been toxic to developing wasp larvae (Wang, personal communication). Microbial spoilage of picked olives under experimental conditions was suggested as a factor limiting reproduction in braconid parasitoids of B. oleae (Sime et al., 2006, 2007; Daane et al., 2008), and may have led us to underestimate proportion parasitism rates in our reared olive samples. However, $P$. nr. myopitae also failed to reproduce in field cages containing fruit on the tree that were infested with third instar B. oleae. This leaves the possibility that confinement of the parasitoids affected their ability to search or detect hosts, or prevented feeding on nutrients necessary for egg maturation. Although provision of honey and water resulted in a 2 month life expectancy for females, we did not test the effects of honey or other nutrient sources on fecundity. Wang (unpublished data) had some success rearing $P$. nr. myopitae offspring in the laboratory in transparent cages provisioned with honey, water, and a protein source (yeast extract), under higher light levels and temperatures than we provided.

Although $P$. nr. myopitae parasitizes only the third instar host, it also probes in fruit containing first and second instars. The parasitoid may detect and locate hosts through sensing vibrations (vibrotaxis) in the substrate made by host movements, a host-finding behavior common among parasitoids that attack mobile stages of hidden hosts (Godfray, 1994). The tephritid parasitoid P. concolor 


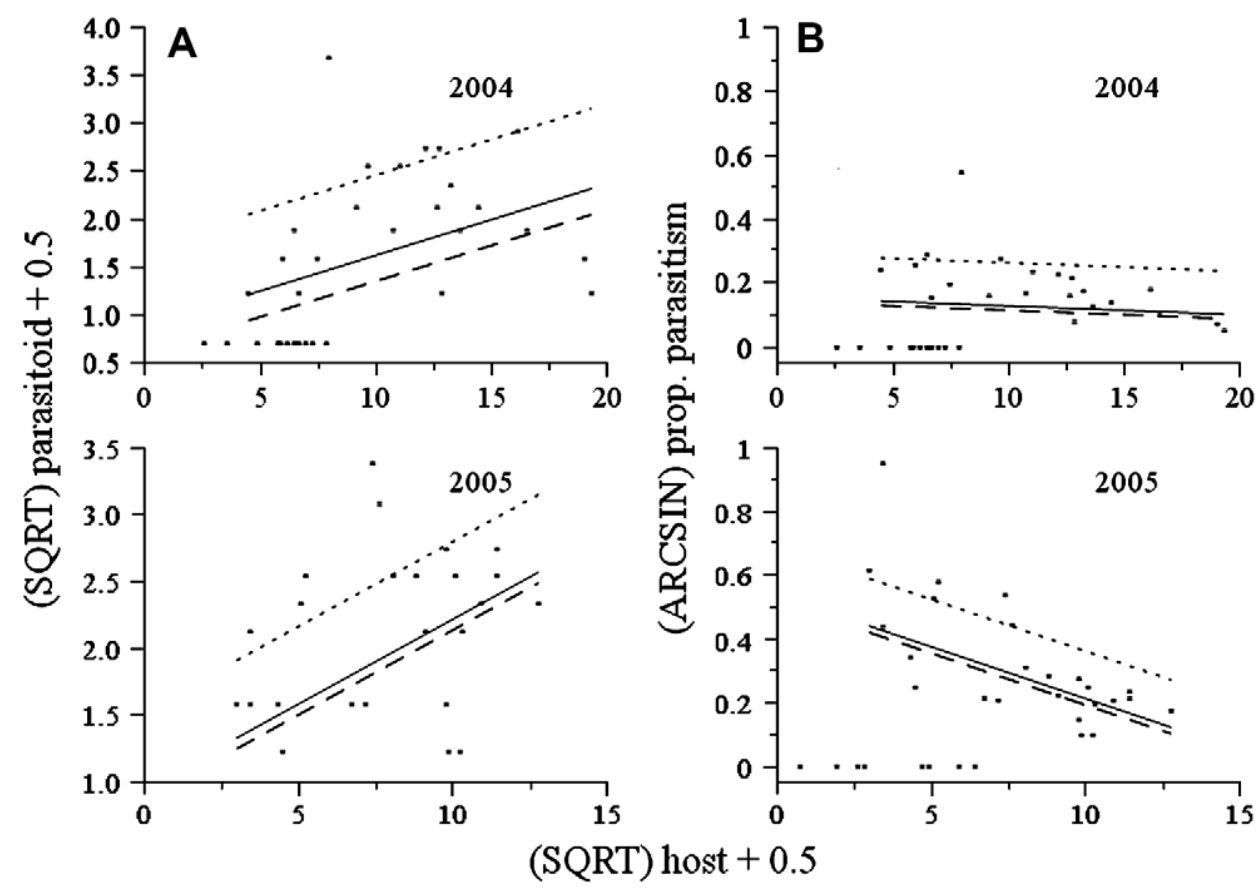

Fig. 5. Slopes of the relationship between Pteromalus nr. myopitae and Bactrocera oleae host numbers in San Luis Obispo sites in 2004 and 2005 , with B. oleae as the covariate in analyses of covariance. (A) Number of parasitoids, (B) proportion parasitism. Dotted line: Grand Avenue, unbroken line: Laurel Lane, dashed line: Monterey Street.

was shown to use vibrotaxis to locate Mediterranean fruit fly larvae (Canale and Loni, 2006), and the third instar host elicited more searching behavior than earlier host instars. The authors suggested that this may be due to stronger substrate vibrations produced by the third instar. Similarly, P. nr. myopitae exhibited more probing behavior in olives containing older instars. Final rejection or acceptance of a host, however, is probably based on chemical or physical cues detected by sensilla at the tip of the ovipositor (Larocca et al., 2007) as it contacts the host.

To our knowledge, the unusual side-mounting copulatory behavior of male $P$. nr. myopitae has been recorded in only one other Pteromalus species (Headrick and Goeden, 1989). Although the behavior may indicate a taxonomic affinity with $P$. coloradensis, we believe it may reflect a necessity by the much smaller male to successfully copulate with a large female possessing an elongated abdomen. Females of both species have attenuated abdomens, and the males are markedly smaller than the females. The female's gonopore is ventrally situated far from the tip of the abdomen in both species, and is probably not reachable by the male's genitalia from her dorsum.

The parasitoid ranges along the Pacific coast from the San Francisco Bay area in California to northwestern Baja, Mexico, as well as the Sacramento Valley and Inland Empire region of Riverside County, but it appears to be rare in the San Joaquin Valley. Whether it sporadically expands its range to the San Joaquin Valley or it is established there but moves from other hosts onto B. oleae when conditions are favorable is unknown. Abiotic factors probably influence both fly and parasitoid dynamics, and likely play a more important role than the parasitoid in moderating $B$. oleae populations. The importance of climatic factors to fly populations is evidenced by similar declines in fly abundance from 2004 to 2006 in SLO, where the parasitoid was present, and in Templeton, where the parasitoid was absent (Fig. 3), although this evidence is based on only a single study site from the Templeton area. The geographical range of $P$. nr. myopitae appears to be at least partly driven by $B$. oleae abundance, which is in turn partly influenced by climate. In California, both fly (Rice et al., 2003, Nadel, unpublished data) and parasitoid are most abundant in coastal regions and least abundant in the San Joaquin Valley. Templeton's more extreme high summer temperatures, which often exceeded $35^{\circ} \mathrm{C}$, may be partly responsible for its lower fly abundance compared with SLO. At such high temperatures, $B$. oleae activity and reproduction are dramatically reduced (Girolami, 1979), and Wang et al. (2009a) demonstrated that this accounts for low fly populations in the San Joaquin Valley when compared with cooler climates. The isolation of Templeton olives from other landscape trees may have also been responsible for its lower fly population. Maximum summer temperatures in the study sites declined from 2004 to 2006, but, contrary to our expectations, fly populations also declined during these years. Undoubtedly, other factors are involved in regional fly and parasitoid abundance.

Overall, our study suggests that $P$. nr. myopitae does not regulate $B$. oleae populations on the California coast, although further study is needed to confirm this. Fly mortality from parasitism appeared to account for only a small portion of the decrease in fly abundance from year to year in SLO, and olive infestation continues to be high in that area (Kapaun, personal observation). Populations of $P$. nr. myopitae possess some attributes that might promote regulation of fly populations, such as increasing with rising fly density and parasitizing greater proportions of flies at lower fly densities, as seen in first two study years before both species plummeted. However, at this point, these relationships can be described only as correlations and we cannot draw conclusions about causal relationships between the two species. In addition, the natural host of $P$. nr. myopitae and its influence on the dynamics of $B$. oleae and the parasitoid are completely unknown. Other biological factors may also influence the dynamics of the fly and parasitoid. Grand Avenue had the lowest fly numbers but highest parasitism rates in SLO; a potential explanation for higher parasitism there is that the site had smaller olive fruit than the other SLO sites, which may allow greater access by the parasitoid to hosts feeding deep within the pulp as demonstrated for other B. oleae parasitoids (Wang et al., 2009b). From an economic perspective, parasitism levels as observed in coastal landscape olives are associated with 


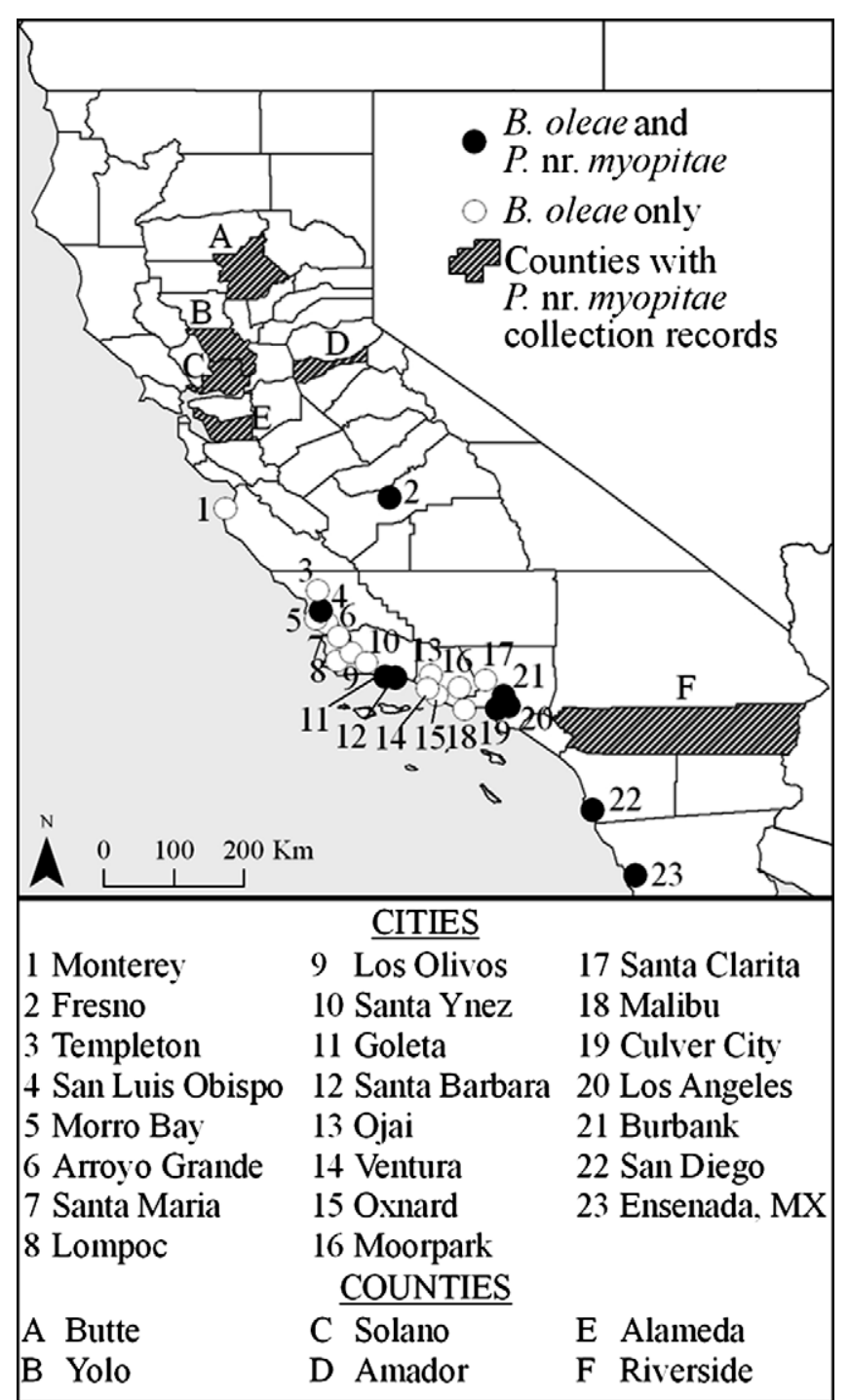

Fig. 6. Range of Pteromalus nr. myopitae. Specific collection sites are shown along the Pacific coast. Inland sample sites are too numerous to show individually.

host populations that are still unacceptably high for the commercial table olive production, which has a zero-tolerance level set by the table olive industry, and furthermore $P$. nr. myopitae attacks late instar hosts that have already rendered the fruit unmarketable. Taken together, these factors indicate poor potential for $P$. nr. myopitae as an effective biological control agent for B. oleae.

Although the unforeseen appearance of $P$. nr. myopitae in California may assist the $B$. oleae control program, it poses a potential conflict with the classical biological control effort now underway, and these interactions should be studied. Idiobiont larval parasitoids may have a competitive advantage over koinobiont species because they immobilize the host, rendering it unusable by the koinobiont, or parasitize it along with the primary host. Idiobionts can utilize hosts previously parasitized by a koinobiont, and kill the koinobiont in the process (Mayhew and Blackburn, 1999; Mitsunaga and Yano, 2004). Of the parasitoid species imported to California, all but $B$. celer are koinobionts. Competition between $B$. celer and $P$. nr. myopitae may also be problematic but the outcome is difficult to predict. To date, however, $B$. celer appears to be less likely to be approved for release in California than the koinobiont species due to its potential risk of harming a beneficial non-target tephritid species (Nadel et al., 2009).
Because P. nr. myopitae was not reported before 2004, we are unable to conclude whether or not the insect is native to North America. In an attempt to locate the native host within the immediate geographic area of our study sites, we sampled host plants of tephritids and other related plants. Because P. myopitae parasitizes several tephritid Myopites species in flower heads of Inula (Asteraceae) in Europe (Jennings, 2005), we sampled flower heads and galls from 29 species of native Asteraceae in SLO County. We also sampled fruits from 26 plant families, as $P$. nr. myopitae has demonstrated an affinity for foraging in olive fruit. However, we failed to locate P. nr. myopitae in any of these collections (Kapaun, 2007). Additionally, the UCR tephritid parasitoid collection did not contain $P$. nr. myopitae, although this extensive collection represents results of a 20-year survey of parasitic wasps reared from native tephritids infesting galls and flower heads of members of Asteraceae from numerous sites in southern California. The absence of the parasitoid from the collection may be due to the vast number of asteraceous species in California, making it unlikely that all 750 species (Keil, personal communication) were sampled. Additionally, a strong possibility exists that $P$. nr. myopitae may not be associated with native hosts in asteraceous plants, as members of the genus Pteromalus are known to have tremendously diverse life histories and a wide range of hosts. The natural host of this species therefore remains unknown pending data from other possible hosts. Nonetheless, the parasitoid is present and established in California, and must be taken into account by classical biological control efforts that are underway. Although field parasitism by this species appears to be low, future field studies of other deliberately introduced biocontrol agents of olive fly in California should consider the impact of possible competition with this species. Pteromalus nr. myopitae should be taxonomically described to facilitate further studies on its life history and its interaction with other biological control agents released against B. oleae in California.

\section{Acknowledgments}

We thank Hannes Baur (Museum of Natural History, Bern, Switzerland) for providing invaluable parasitoid identification and taxonomic advice. Steve Heydon (UC Davis) is currently preparing a species description. Julie Howar prepared the map, and Marshall W. Johnson (UCR) allowed us to use a color photograph of the parasitoid. David Keil (CPSU) identified plant specimens for the SLO Asteraceae collection. We also thank Xin-geng Wang (UCR) for sharing unpublished rearing information on the parasitoid, Martha Gerik (KAC) for providing custom-ordered uninfested olives, Frances Snyder for creating the outdoor sleeved cages, and two anonymous reviewers for their suggestions on improving the manuscript.

\section{References}

Barrio, O.S., Carman, H., 2005. Olive oil: a "rediscovered" California crop. University of California Giannini Foundation Update, Agricultural and Resource Economics $8(5), 1-4$.

Canale, A., Loni, A., 2006. Host location and acceptance in Psyttalia concolor: role of host instar. Bulletin of Insectology 59, 7-10.

Daane, K.M., Rice, R.E., Zalom, F.G., Barnett, W.W., Johnson, M.W., 2005. Arthropod pests of olive. In: Sibbett, G.S., Ferguson, L. (Eds.), Olive Production Manual, second ed. University of California Agriculture and Natural Resources Publication 3353, Oakland, CA, pp. 105-114.

Daane, K.M., Sime, K.R., Wang, X., Nadel, H., Johnson, M.W., Walton, V.M., 2008 Psyttalia lounsburyi (Hymenoptera: Braconidae), potential biological control agent for the olive fruit fly in California. Biological Control 44, 79-89.

Girolami, V., 1979. Studi biologici e demoecologici sul Dacus oleae (Gmelin). Redia 62, 147-191.

Godfray, H.C.J., 1994. Parasitoids: Behavioral and Evolutionary Ecology. Princeton University Press, Princeton, NJ

Goulet, H., Huber, J., 1993. Hymenoptera of the World: An Identification Guide to Families. Agriculture Canada Research Branch Publication 1894/E, Ottawa, Canada.

Headrick, D.H., Goeden, R.D., 1989. Life history of Pteromalus coloradensis (Ashmead) (Hymenoptera: Pteromalidae) a parasite of Paracantha gentilis Hering (Diptera: 
Tephritidae) in Cirsium thistle capitula. Proceedings of the Entomological Society of Washington 91, 594-603.

Hoelmer, K., Kirk, A., Wharton, R., Pickett, C., 2004. Foreign exploration for parasitoids of the olive fruit fly, Bactrocera oleae. In: Woods, D. (Ed.), Biological Control Program Annual Summary, 2003. California Department of Food and Agriculture, Sacramento, pp. 12-14

Jennings, M.T., 2005. Chalcidoidea (Hymenoptera) reared from galls of Myopites eximius Seguy, 1932, and Myopites inulaedyssentericae Blot, 1827 (Diptera: Tephritidae) collected in Kent. Entomologist's Gazette 56 (1), 47-50.

Kapaun, T.A., 2007. Biology and parasitism rates of Pteromalus nr. myopitae (Hymenoptera: Pteromalidae), a newly discovered parasitoid of olive fly in coastal California. M.Sc. Thesis, California Polytechnic State University, San Luis Obispo, CA.

Larocca, A., Fanti, P., Romano, V.A., Mariscovetere, E., Isidoro, N., Romani, R., Ruschioni, S., Pennacchio, F., Battaglia, D., 2007. Functional bases of hostacceptance behaviour in the aphid parasitoid Aphidius ervi. Physiological Entomology 32 (4), 35-312.

Mayhew, P.J., Blackburn, T.M., 1999. Does development mode organize life-history traits in the parasitoid Hymenoptera? Journal of Animal Ecology 68, 906-916.

Minitab, 2008. Version 15.2, Minitab Inc., College Station, PA.

Mitsunaga, T., Yano, E., 2004. The effect of multiple parasitism by an endoparasitoid on several life history traits of leafminer ectoparasitoids. Applied Entomology and Zoology 39, 315-320.

Nadel, H., Daane, K.M., Hoelmer, K.A., Pickett, C.H., Johnson, M.W., 2009. Non-target host risk assessment of the idiobiont parasitoid Bracon celer (Hymenoptera: Braconidae) for biological control of olive fruit fly in California. Biocontrol Science and Technology 97, 701-715.

Neuenschwander, P., 1982. Searching parasitoids of Dacus oleae (Gmel.) (Dipt., Tephritidae) in South Africa. Zeitschrift für angewandte Entomologie 94, 509522.
Pickett, C.H., Rodriguez, R., 2004. Indigenous Pteromalus on olive fruit fly. In: Woods, D.M. (Ed.) 2003 Biological Control Program Annual Summary. California Department of Food and Agriculture, Plant Health and Pest Prevention Services, Sacramento, CA, pp. 7-8.

Rice, R.E., Philips, P.A., Stewart-Leslie, J., Sibbett, G.S., 2003. Olive fruit fly populations measured in central and southern California. California Agriculture 57, 122-127.

SAS 2008. JMP version 8.0. SAS Institute, Inc., Cary, NC

Silvestri, F., 1914. Report of an Expedition to Africa in Search of the Natural Enemies of Fruit Flies (Trypaneidae) with Descriptions, Observations and Biological Notes. Board of Agriculture and Forestry, Terr. Hawaii, Bull. 3, 1-146.

Sime, K.R., Daane, K.M., Andrews Jr., J.W., Hoelmer, K., Pickett, C.H., Nadel, H., Johnson, M.W., Messing, R.H., 2006. The biology of Bracon celer as a parasitoid of the olive fruit fly. Biocontrol 51, 553-567.

Sime, K.R., Daane, K.M., Kirk, A., Andrews, J.W., Johnson, M.W., Messing, R.H., 2007. Psyttalia ponerophaga (Hymenoptera: Braconidae) as a potential biological control agent of olive fruit fly Bactrocera oleae (Diptera: Tephritidae) in California. Bulletin of Entomological Research 97, 233-242.

Universal Chalcidoidea Database, 2007. The Natural History Museum, London, UK. Available from: <http://www.nhm.ac.uk/jdsml/research-curation/research/ projects/chalcidoids> (accessed 18.06.07).

Vossen, P., Varela, L., Devarenne, A., 2005. Olive fruit fly. University of California Cooperative Extension, Sonoma County Publication. Available from: <http:// cesonoma.ucdavis.edu/hortic/pdf/olive_fruit_fly_info.pdf> (accessed 20.10.08).

Wang, X., Johnson, M.W., Daane, K.M., Nadel, H., 2009a. High summer temperatures impact survival and reproduction of olive fruit fly (Diptera: Tephritidae). Environmental Entomology 38, 1496-1504.

Wang, X., Nadel, H., Johnson, M.W., Daane, K.M., Hoelmer, K., Walton, V.M., Pickett, C.H., Sime, K.R., 2009b. Crop domestication relaxes both top-down and bottomup effects on a specialist herbivore. Basic and Applied Ecology 10, 216-227. 